\title{
Cyclotron Production and Separation of Scandium Radionuclides from Natural Titanium Metal and Titanium Dioxide Targets
}

\author{
C. Shaun Loveless ${ }^{1,2}$, Jose R. Blanco ${ }^{3}$, George L. Diehl $\mathrm{III}^{4}$, Rawdah T. Elbahrawi ${ }^{5}$, Tommaso S. Carzaniga ${ }^{6}$, \\ Saverio Braccini ${ }^{6}$, and Suzanne E. Lapi ${ }^{1,3}$
}

${ }^{1}$ Department of Radiology, University of Alabama at Birmingham, Birmingham, Alabama; ${ }^{2}$ Department of Chemistry, Washington University in St. Louis, St. Louis, Missouri; ${ }^{3}$ Department of Chemistry, University of Alabama at Birmingham, Birmingham, Alabama; ${ }^{4}$ Department of Chemistry, Vassar College, Poughkeepsie, New York; ${ }^{5}$ Department of Biomedical Engineering, University of Alabama at Birmingham, Birmingham, Alabama; and ${ }^{6}$ Albert Einstein Center for Fundamental Physics, University of Bern, Bern, Switzerland

\begin{abstract}
Theranostic strategies involve select radionuclides that allow diagnostic imaging and tailored radionuclide therapy in the same patient. An example of a Food and Drug Administration-approved theranostic pair is the ${ }^{68} \mathrm{Ga}$ - and ${ }^{177} \mathrm{Lu}$-labeled DOTATATE peptides, which are used to image neuroendocrine tumors, predict treatment response, and treat disease. However, when using radionuclides of 2 different elements, differences in the pharmacokinetic and pharmacodynamic profile of the agent can occur. Theranostic agents that incorporate the matched-pair radionuclides of scandium $-{ }^{43} \mathrm{Sc} /{ }^{47} \mathrm{Sc}$ or ${ }^{44} \mathrm{Sc} /{ }^{47} \mathrm{Sc}$ - would guarantee identical chemistries and pharmacologic profiles. The aim of this study was to investigate production of $43,44,47 \mathrm{Sc}$ via proton-induced nuclear reactions on titanium nuclei using a $24-\mathrm{MeV}$ cyclotron. Methods: Aluminum, niobium, and tantalum target holders were used with titanium foils and pressed $\mathrm{TiO}_{2}$ to produce scandium radionuclides with proton energies of up to $24 \mathrm{MeV}$. Irradiated targets were digested using $\mathrm{NH}_{4} \mathrm{HF}_{2}$ and $\mathrm{HCl}$ in a closed perfluoroalkoxy alkane vessel in $90 \mathrm{~min}$. Scandium radionuclides were purified via ion-exchange chromatography using branched $N, N, N^{\prime}, N^{\prime}$-tetra2-ethylhexyldiglycolamide. The titanium target material was recovered via alkali precipitation with ammonia solution. Results: Titanium foil and $\mathrm{TiO}_{2}$ were digested with an average efficiency of $98 \% \pm 3 \%$ and $95 \% \pm 1 \%$, respectively. The typical digestion time was $45 \mathrm{~min}$ for titanium foil and $75 \mathrm{~min}$ for $\mathrm{TiO}_{2}$. The average scandium recovery was $94 \% \pm 3 \%$, and the average titanium recoveries from digested titanium foil and $\mathrm{TiO}_{2}$ after precipitation as $\mathrm{TiO}_{2}$ were $108 \% \pm 8 \%$ and $104 \% \pm 5 \%$ of initial mass, respectively. Conclusion: This work demonstrated a robust method for the cyclotron production of scandium radionuclides that could be used with natural or enriched $\mathrm{TiO}_{2}$ target material.
\end{abstract}

Key Words: ${ }^{43} \mathrm{Sc} ;{ }^{44} \mathrm{Sc}$; ${ }^{47} \mathrm{Sc}$; titanium digestion; BDGA; cyclotron production

J Nucl Med 2021; 62:131-136

DOI: 10.2967/jnumed.120.242941

Received Feb. 4, 2020; revision accepted May 28, 2020.

For correspondence or reprints contact: Suzanne E. Lapi, University of Alabama at Birmingham, 1720 2nd Ave. S., Birmingham, AL 35294.

E-mail: lapi@uab.edu

Published online Jul. 3, 2020.

COPYRIGHT (C 2021 by the Society of Nuclear Medicine and Molecular Imaging.
$\mathbf{T}$ he element scandium has 3 radionuclides with properties suitable for diagnostic and therapeutic applications in nuclear medicine. ${ }^{43} \mathrm{Sc}$ (half-life $\left[\mathrm{t}_{1 / 2}\right]=3.89 \mathrm{~h}$ ) and ${ }^{44} \mathrm{Sc}\left(\mathrm{t}_{1 / 2}=3.97 \mathrm{~h}\right.$ ) undergo positron decay, with $\beta^{+}{ }_{\text {mean }}$ energies of $476.0 \mathrm{keV}(88.1 \%)$ and $632.0 \mathrm{keV}$ (94.3\%), respectively, making them well suited for PET (1). ${ }^{47} \mathrm{Sc}\left(\mathrm{t}_{1 / 2}=3.35 \mathrm{~d}\right)$ undergoes $\beta$-decay, with a $\beta^{-}$mean energy of $162 \mathrm{keV}$ to ${ }^{47} \mathrm{Ti}$, followed by emission of a $159-\mathrm{keV}$ $\gamma$-ray $(68.4 \%)(1)$. Thus, ${ }^{47} \mathrm{Sc}$ might be used for targeted radionuclide therapy and SPECT. These radionuclides of scandium might be used to create theranostic agents for diagnostic imaging and targeted radiotherapy in the same patient.

Interest in these radionuclides is partly motivated by the recent clinical success of DOTATATE and results in clinical trials investigating small-molecule inhibitors of prostate-specific membrane antigen (PSMA). DOTATATE, a somatostatin analog, labeled with ${ }^{68} \mathrm{Ga}\left(\mathrm{t}_{1 / 2}=67.7 \mathrm{~min}\right)$ or ${ }^{177} \mathrm{Lu}\left(\mathrm{t}_{1 / 2}=6.7 \mathrm{~d}\right)$ can be used in theranostics to diagnose and treat SSTR-expressing neuroendocrine tumors (2,3). Similarly, inhibitors of PSMA such as PSMA-11, PSMA-617, DCFPyL, and MIP-1072 labeled with ${ }^{68} \mathrm{Ga},{ }^{177} \mathrm{Lu},{ }^{18} \mathrm{~F}\left(\mathrm{t}_{1 / 2}=109.7 \mathrm{~min}\right),{ }^{131} \mathrm{I}\left(\mathrm{t}_{1 / 2}=8.0 \mathrm{~d}\right),{ }^{123} \mathrm{I}\left(\mathrm{t}_{1 / 2}=\right.$ $13.2 \mathrm{~h})$, or ${ }^{99 \mathrm{mTc}}\left(\mathrm{t}_{1 / 2}=6 \mathrm{~h}\right)$ can be used for diagnosis and treatment of PSMA-positive prostate cancer $(1,4)$. Theranostic agents that incorporate radionuclides of different elements can have differences in their in vivo kinetics (5). The selection of a matched pair (e.g., ${ }^{43 / 47} \mathrm{Sc}$ ), guarantees identical pharmacodynamic and pharmacokinetic profiles and provides the truest picture of in vivo distribution before radionuclide therapy. Further, the $t_{1 / 2}$ of ${ }^{43} \mathrm{Sc}$ and ${ }^{44} \mathrm{Sc}$, in contrast to ${ }^{68} \mathrm{Ga}$, could allow for imaging at extended time points (6). Therefore, development of efficient methods to produce ${ }^{43,44,47} \mathrm{Sc}$ is an important first step to translating these matched-pair radionuclides of scandium to the clinic.

${ }^{43} \mathrm{Sc}$ and ${ }^{44} \mathrm{Sc}$ can be produced via multiple routes. Accelerator production using $\alpha$-particles, protons, and deuterons on calcium and titanium nuclei has been investigated for the ${ }^{\text {nat }} \mathrm{Ca}(\alpha, \mathrm{x})^{43,44,47} \mathrm{Sc}$, ${ }^{42} \mathrm{Ca}(\mathrm{d}, \mathrm{n}){ }^{43} \mathrm{Sc}, \quad{ }^{43} \mathrm{Ca}(\mathrm{p}, \mathrm{n}){ }^{43} \mathrm{Sc}, \quad{ }^{44} \mathrm{Ca}(\mathrm{p}, 2 \mathrm{n}){ }^{43} \mathrm{Sc}, \quad{ }^{46} \mathrm{Ti}(\mathrm{p}, \alpha){ }^{43} \mathrm{Sc}$, ${ }^{47} \mathrm{Ti}(\mathrm{p}, \alpha){ }^{44} \mathrm{Sc},{ }^{44} \mathrm{Ca}(\mathrm{p}, \mathrm{n}){ }^{44} \mathrm{Sc}$, ${ }^{\text {nat }} \mathrm{Ca}(\mathrm{p}, \mathrm{n}){ }^{44} \mathrm{Sc}$, and ${ }^{44} \mathrm{Ca}(\mathrm{d}, 2 \mathrm{n}){ }^{44} \mathrm{Sc}$ nuclear reactions (7-13). The use of calcium and titanium has been shown to provide gigabecquerels and hundreds of megabecquerels of ${ }^{43} \mathrm{Sc}$ and ${ }^{44} \mathrm{Sc}$, depending on beam current and irradiation time; however, ${ }^{44} \mathrm{Sc}$ produced by these reactions will result in the coproduction of its nuclear isomer, ${ }^{44 \mathrm{~m}} \mathrm{Sc}\left(\mathrm{t}_{1 / 2}=58.6 \mathrm{~h}\right)$. 
The presence of this longer-lived metastable state may complicate patient dosimetry. ${ }^{44} \mathrm{Sc}$ may be obtained without its nuclear isomer from a ${ }^{44} \mathrm{Ti}\left(\mathrm{t}_{1 / 2}=59.2 \mathrm{y}\right)$ generator $(14)$.

${ }^{47} \mathrm{Sc}$ can also be produced via multiple routes. Reactor production of ${ }^{47} \mathrm{Sc}$ has been investigated using fast neutrons on enriched titanium via the ${ }^{47} \mathrm{Ti}(\mathrm{n}, \mathrm{p}){ }^{47} \mathrm{Sc}$ reaction (neutron energy $>1 \mathrm{MeV}$ ) or thermal neutrons (neutron energy $=0.025 \mathrm{eV}$ ) on enriched calcium via the ${ }^{46} \mathrm{Ca}(\mathrm{n}, \gamma){ }^{47} \mathrm{Ca} \rightarrow{ }^{47} \mathrm{Sc}$ reaction for a ${ }^{47} \mathrm{Ca}-{ }^{47} \mathrm{Sc}\left(\mathrm{t}_{1 / 2}=4.5 \mathrm{~d}\right)$ generator system (15). One challenge facing development of a ${ }^{47} \mathrm{Ca}-{ }^{47} \mathrm{Sc}$ generator is the natural abundance of ${ }^{46} \mathrm{Ca}(0.004 \%)$. ${ }^{47} \mathrm{Sc}$ may also be produced by the ${ }^{48} \mathrm{Ti}(\gamma, \mathrm{p})^{47} \mathrm{Sc}$ reaction using bremsstrahlung radiation, and accelerator production by the ${ }^{48} \mathrm{Ca}(\mathrm{p}, 2 \mathrm{n}){ }^{47} \mathrm{Sc}$ reaction was investigated at $18 \mathrm{MeV}$ and resulted in a saturation yield of $12 \mathrm{GBq} / \mu \mathrm{A}(16-19)$.

Unlike production routes using calcium, the use of titanium could allow production on a single proton accelerator using a unified separation methodology that applies identical targetry and target-processing chemistries and results in better radionuclidic purity for ${ }^{43,44,47} \mathrm{Sc}$. However, the magnitude of the cross section for reactions on titanium are much less than those on calcium at lower energies (16-18 MeV). Favorably, the cross-section values increase at the higher energies $(\leq 24 \mathrm{MeV})$ used in this study. Multiple challenges must be addressed to produce scandium radionuclides from stable nuclei of titanium using this unified approach. First, the powdery $\mathrm{TiO}_{2}$ targets require a holder that encapsulates the irradiated material to prevent radiologic contamination. Next, the slow $\mathrm{TiO}_{2}$ digestion kinetics and short $\mathrm{t}_{1 / 2}$ of ${ }^{43} \mathrm{Sc} /{ }^{44} \mathrm{Sc}$ necessitate development of a rapid digestion method. Lastly, ${ }^{43,44,47} \mathrm{Sc}$ with high radionuclidic purity can be obtained only using enriched titanium, since ${ }^{46,47,50} \mathrm{Ti}$ has natural abundances of $8.25 \%, 7.44 \%$, and $5.18 \%$, respectively. Thus, efficient recycling chemistry must be developed to recover and reuse the enriched target material.

To address these challenges, methods were developed to investigate ${ }^{43,44,47} \mathrm{Sc}$ yields and purification chemistry using natural titanium and $\mathrm{TiO}_{2}$. The results from this work suggest that ${ }^{43,44,47} \mathrm{Sc}$ might be produced at energies of up to $24 \mathrm{MeV}$ using enriched $\mathrm{TiO}_{2}$ and purified using a unified methodology to supply quantities needed for the preclinical evaluation of these matched-pair radionuclides.

\section{MATERIALS AND METHODS}

\section{Reagents}

All chemicals were of analytic or trace metals grade. Deionized 18.2 M $\Omega$-cm water (Milli-Q System; Millipore) was used unless otherwise specified. Ammonium bifluoride $\left(\mathrm{NH}_{4} \mathrm{HF}_{2}, 99.999 \%\right)$, hydrochloric acid ( $\mathrm{HCl}, 37 \%$ by weight, $99.999 \%), 25 \%$ ammonia solution $\left(\mathrm{NH}_{4} \mathrm{OH}\right.$, EMSURE; Merck), $\mathrm{TiO}_{2}$ (anatase form, 99.8\%), periodic table analytic standards (mix 1, $10 \mathrm{mg} / \mathrm{L}$, TraceCERT; SigmaAldrich), ammonium acetate $\left(\mathrm{CH}_{3} \mathrm{CO}_{2} \mathrm{NH}_{4}, 99.999 \%\right)$, and nitric acid $\left(\mathrm{HNO}_{3}, 70 \%\right.$ by weight, $\left.99.999 \%\right)$ were purchased from SigmaAldrich. Analytic standards containing titanium $(1,000 \mathrm{mg} / \mathrm{L})$ and scandium $(1,000 \mathrm{mg} / \mathrm{L})$ were purchased from Agilent. Analytic-grade $N, N, N^{\prime}, N^{\prime}$-tetra-2-ethylhexyldiglycolamide (branched DGA resin) was purchased from Eichrom Technologies. DOTA was purchased from Macrocyclic. All glassware was cleaned in a $50 \% \mathrm{HNO}_{3}$ bath overnight.

\section{Target Holders}

Multiple target holders were developed to mount and irradiate titanium foil and $\mathrm{TiO}_{2}$ target materials. The disk-shaped 2-mm-thick target holders fabricated from aluminum, tantalum, and niobium are shown in Figure 1. The aluminum target holder had a circular base and

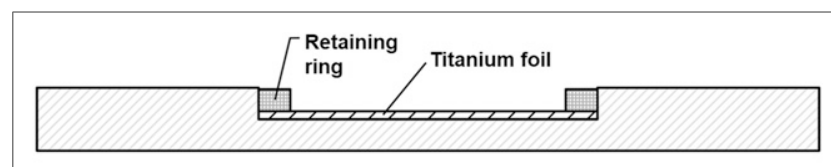

Niobium target holder assembly

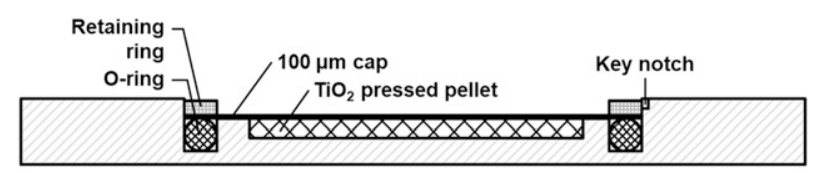

Tantalum target holder assembly

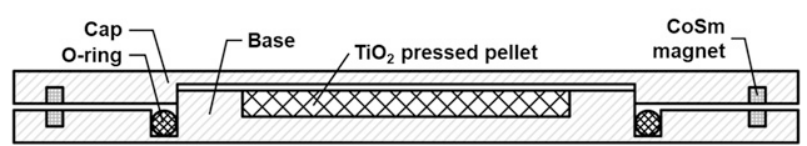

Aluminum target holder assembly

FIGURE 1. Target holder assemblies tested in this work.

cap secured by samarium-cobalt magnets. A fluoroelastomer o-ring was integrated between the base and cap to enclose the target material. A bore $(\emptyset=7 \mathrm{~mm})$ was centered in the base. The niobium target holder contained a centered bore $(\emptyset=10 \mathrm{~mm})$ holding titanium foil, which was secured against the base using a 10.1-mm single-turn spiral internal retaining ring (Smalley). The tantalum target holder contained a centered bore $(\emptyset=10 \mathrm{~mm})$ with an integrated o-ring between the base and cap to enclose the target material. The bore held a $\mathrm{TiO}_{2}$ disk that was secured by placing a $100-\mu \mathrm{m}$ titanium disk atop the bore and o-ring. The titanium disk was held in place by a $14.3-\mathrm{mm}$ spiral retaining ring (Rotor Clip). Stopping and range of ions in matter (SRIM) was used to determine the optimal thickness of each target holder to stop 17- or 24-MeV protons (20).

\section{Preparation of Target Material}

Titanium foil targets were prepared using a $10-\mathrm{mm}$ punch and die (Precision Brand Products). Before pressing, $\mathrm{TiO}_{2}$ was dried overnight at $230^{\circ} \mathrm{C}$ in a vacuum oven at $0.3 \mathrm{~Pa}$. Approximately 35 or $70 \mathrm{mg}$ of $\mathrm{TiO}_{2}$ were transferred into a clean 7 - or $10-\mathrm{mm}$ die (Specac) and pressed for $5 \mathrm{~min}$ at 4 tons of pressure on a manual press (Carver). Additional $\mathrm{TiO}_{2}$ was iteratively added and pressed. This process was repeated twice, with a final target mass of approximately 52 or $110 \mathrm{mg}$.

\section{Cyclotron Parameters}

Irradiation was conducted on a TR-24 cyclotron (Advanced Cyclotron Systems). ${ }^{43} \mathrm{Sc},{ }^{44} \mathrm{Sc}$, and ${ }^{47} \mathrm{Sc}$ were produced via the ${ }^{\text {nat }} \mathrm{Ti}(\mathrm{p}, \mathrm{x})$ nuclear reaction at 17 and $24 \mathrm{MeV}$. Titanium and $\mathrm{TiO}_{2}$ targets were mounted at a $90^{\circ}$ angle and bombarded at beam currents of up to 40 and $30 \mu \mathrm{A}$, respectively. The targets were cooled by high-pressure, low-flow helium gas (275-345 kPa, $1 \mathrm{~L} / \mathrm{min})$ on the front and pumped water $(2-3 \mathrm{~L} / \mathrm{min})$ on the back. Bombarded targets were allowed to decay for $1-5 \mathrm{~h}$ to allow for the decay of coproduced ${ }^{47} \mathrm{~V}\left(\mathrm{t}_{1 / 2}=32.6 \mathrm{~min}\right)$.

\section{Production Yields}

The radionuclidic yields were determined using a high-purity germanium detector. Predicted yields were calculated using nuclear data retrieved from the Experimental Nuclear Reaction Data database $(21,22)$. The code SRIM was used to model the entrance and exit proton energies. End-of-bombardment yields were determined using Mathcad (version 14.0) and Equation 1, where $\mathrm{N}_{\mathrm{A}}$ is the Avogadro constant (atoms $/ \mathrm{mol}$ ), I is incident particle flux (particles/s), $\mathrm{A}_{\mathrm{T}}$ is the atomic weight $(\mathrm{g} / \mathrm{mol}), \lambda$ is the decay constant $(1 / \mathrm{s}), t$ is the irradiation 
time (s), $E_{0}$ is the initial proton energy, $E_{e}$ is the exit proton energy, $\sigma(E)$ is the energy-dependent reaction cross section $\left(\mathrm{cm}^{2}\right)$, and $\mathrm{S}(\mathrm{E})$ is the total stopping power $\left(\mathrm{MeV} / \mathrm{cm}^{2} / \mathrm{g}\right)(23)$.

$$
\text { Yield }=\frac{N_{A} I}{A_{T}}\left(1-e^{-\lambda t}\right) \int_{E_{e}}^{E_{0}} \sigma(E) \frac{d E}{S(E)}
$$

\section{Determination of Equilibrium Dissociation Constant}

The equilibrium dissociation constant was determined following a previously reported method (24). The dissociation constants were calculated using Equation 2, where $\mathrm{C}_{\text {resin }}$ is the concentration of radioactivity adsorbed onto the resin, $\mathrm{C}_{\text {aqueous }}$ is the concentration of radioactivity in the solvent, $A_{i}$ is the radioactivity in filtered supernatant $(\mathrm{Bq}), \mathrm{V}$ is the volume of the filtered supernatant $(\mathrm{mL})$, and $\mathrm{m}$ is the mass of the resin $(\mathrm{g})$.

$$
\text { Dissociation constant }=\frac{\mathrm{C}_{\text {resin }}}{\mathrm{C}_{\mathrm{aqueous}}}=\frac{\mathrm{A}_{\mathrm{i}}-\mathrm{A}_{\mathrm{eq}}}{\mathrm{A}_{\mathrm{eq}}} \cdot \frac{\mathrm{m}}{\mathrm{V}} \quad \text { Eq. } 2
$$

\section{Digestion of Titanium Foil and $\mathrm{TiO}_{2}$}

Irradiated titanium was transferred into a conical 15-mL screw-cap perfluoroalkoxy alkane vial (Savillex) containing approximately 200 $\mathrm{mg}$ of $\mathrm{NH}_{4} \mathrm{HF}_{2}$ dissolved in $3 \mathrm{~mL}$ of $12.1 \mathrm{M} \mathrm{HCl}$. The vial was capped and heated at $230^{\circ} \mathrm{C}$ for $45 \mathrm{~min}$. Irradiated $\mathrm{TiO}_{2}$ was transferred into a conical $15-\mathrm{mL}$ screw-cap vial and mixed with $\mathrm{NH}_{4} \mathrm{HF}_{2}$ (1:3 ratio). The vial was capped and heated to $230^{\circ} \mathrm{C}$ for $45 \mathrm{~min}$. After heating, the dry residue was dissolved by adding $5 \mathrm{~mL}$ of $12.1 \mathrm{M} \mathrm{HCl}$ and heating the closed vessel for $45 \mathrm{~min}$ in a silicone-oil bath at $160^{\circ} \mathrm{C}$. For both digestion methods, samples were taken in triplicate, filtered, and diluted in $2 \% \mathrm{HNO}_{3}$ for trace metal analyses. The digestion methods are illustrated in Figure 2.

\section{Branched DGA Resin Separation}

Approximately $110 \mathrm{mg}$ of branched DGA resin were stirred in a vortex mixer with $5 \mathrm{~mL}$ of $7 \mathrm{M} \mathrm{HNO}_{3}$. The mixture was transferred into a $0.8 \times 9 \mathrm{~cm}$ polypropylene column (Bio-Rad), the $\mathrm{HNO}_{3}$ was eluted, and a glass wool plug was placed on the resin bed (7-mm height). A flow rate of $1.0 \mathrm{~mL} / \mathrm{min}$ was used for each eluent. The resin was washed with $5 \mathrm{~mL}$ each of $7 \mathrm{M} \mathrm{HNO}_{3}$, water, $0.1 \mathrm{M} \mathrm{HCl}$, and $7 \mathrm{M} \mathrm{HCl}$. The digestant was loaded onto the column in approximately 7-8 M HCl. Eluent $1(20 \mathrm{~mL}, 7 \mathrm{M} \mathrm{HCl})$, eluent $2(10 \mathrm{~mL}, 7 \mathrm{M}$

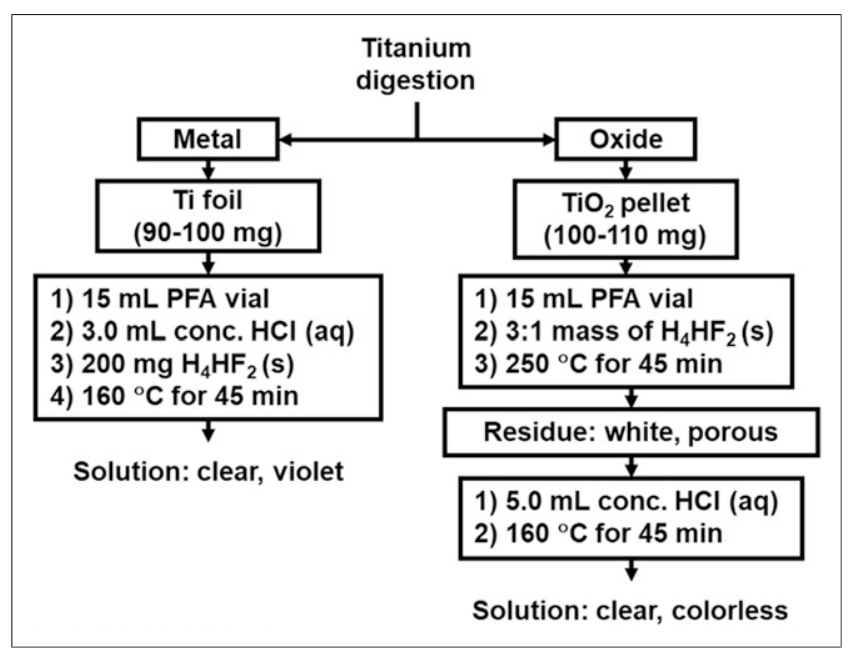

FIGURE 2. Methods for digestion of titanium foil and $\mathrm{TiO}_{2}$. PFA = perfluoroalkoxy alkane.
$\left.\mathrm{HNO}_{3}\right)$, and eluent $3(10 \mathrm{~mL}, 0.1 \mathrm{M} \mathrm{HCl})$ were passed through the column and collected. The final eluate containing the scandium radionuclides was collected into a $10-\mathrm{mL}$ conical vial and evaporated to dryness under vacuum at $100^{\circ} \mathrm{C}$. After evaporation, the purified scandium was reconstituted in $0.5 \mathrm{M} \mathrm{CH}_{3} \mathrm{CO}_{2} \mathrm{NH}_{4}$ buffer ( $\mathrm{pH} 4.7$ ). The separation method is shown in Figure 3.

Samples were taken from each eluate and analyzed to determine the distribution of titanium and vanadium and the percentage recovery of scandium. The decontamination factor $\left(\mathrm{D}_{\mathrm{A}, \mathrm{B}}\right)$, a measure of the scandium purification, was determined using Equation 3, giving the change in ratio of constituent 1 (A) to constituent 2 (B), $Q_{A, 0}$ is the initial amount of $A, Q_{A}$ is the final amount of $A, Q_{B, 0}$ is the initial amount of $\mathrm{B}$, and $\mathrm{Q}_{\mathrm{B}}$ is the final amount of $\mathrm{B}(25)$.

$$
\mathrm{D}_{\mathrm{A}, \mathrm{B}}=\frac{\mathrm{Q}_{\mathrm{A}}}{\mathrm{Q}_{\mathrm{A}, 0}} \times \frac{\mathrm{Q}_{\mathrm{B}, 0}}{\mathrm{Q}_{\mathrm{B}}}
$$

\section{3,44,47Sc-PSMA-617 Radiolabeling and Cell Uptake Studies}

The bioconjugate PSMA-617 was labeled with ${ }^{43,44,47} \mathrm{Sc}(10 \mathrm{MBq} / \mathrm{nmol})$ and characterized by high-performance liquid chromatography using 2 solvents. Solvent A was acetonitrile with $0.1 \%$ trifluoroacetic acid, and solvent $\mathrm{B}$ was water with $0.1 \%$ trifluoroacetic acid. The linear gradient was $5 \%$ A:95\% B to $80 \%$ A:20\% B over 15 min at $0.7 \mathrm{~mL} /$ min. The specific uptake of the radioligand to PSMA receptors was demonstrated via a blocking study using the PSMA inhibitor 2-(phosphonomethyl)pentanedioic acid. The PSMA-negative PC3 cell line was used as a control. The concentration of the inhibitor was $100 \mu \mathrm{M}$.

\section{Alkali Precipitation of Titanium}

Eluate containing titanium was diluted to $500 \mathrm{~mL}$ with water and heated for $45 \mathrm{~min}$ at $160^{\circ} \mathrm{C}$. While it was being stirred, the $\mathrm{pH}$ was adjusted to 8 by dropwise addition of $19 \mathrm{~mL}$ of $25 \%$ ammonia solution. The stir bar was removed, and the precipitate was allowed to settle for $1 \mathrm{~h}$. The mixture was vacuum-filtered with a grade 43 ashless filter paper (Cytiva) and rinsed twice with $10 \mathrm{~mL}$ of $1 \%$ aqueous ammonia solution. The precipitate was washed with $10 \mathrm{~mL}$ of acetone. The filter paper was transferred to a zirconia crucible and combusted in a tube furnace at $1,000^{\circ} \mathrm{C}$ for $24 \mathrm{~h}$.

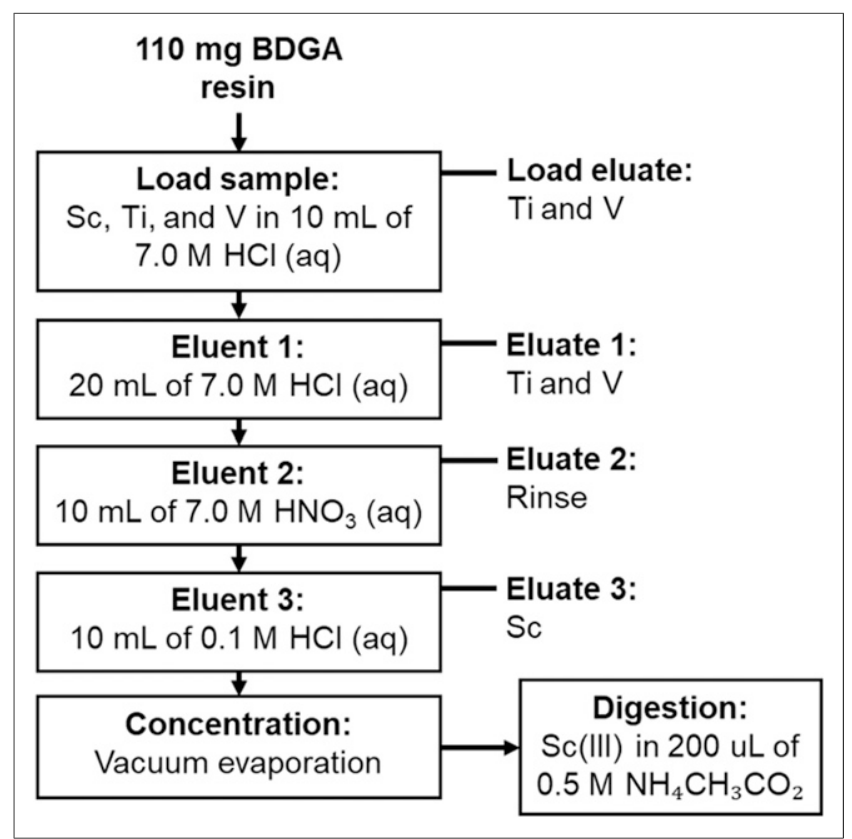

FIGURE 3. Schematic of ${ }^{43,44,47} \mathrm{Sc}$ separation. 


\section{High-Purity Germanium Spectroscopy}

Radioactive samples were characterized by $\gamma$-ray spectroscopy using a Canberra GC2018 high-purity germanium detector with an intrinsic efficiency of $24.5 \%$ connected to a DSA-100 multichannel analyzer. Canberra Genie 2000 software was used for data acquisition and analysis. An energy and efficiency calibration was performed using a mixed nuclide source in a sealed $1.5-\mathrm{mL}$ microcentrifuge vial prepared by Eckert and Ziegler Analytics. Efficiency-calibration spectra with a minimum photopeak area of $2 \times 10^{5}$ counts were collected and fit to determine the relative detector efficiency. For all measurements, aliquots of sample material were diluted to $1 \mathrm{~mL}$ in a $1.5-\mathrm{mL}$ vial and suspended in an acrylic holder at a distance of 5 or $25 \mathrm{~mm}$ from the high-purity germanium detector. These geometries were maintained for all sample measurements.

\section{Inductively Coupled Plasma Mass Spectrometry (ICP-MS)}

Samples containing stable elements were preserved and analyzed via ICP-MS. Multielement standards in $2 \% \mathrm{HNO}_{3}$ at $0.1,1,10,100$, and $1,000 \mu \mathrm{g} / \mathrm{L}$ were used for instrument calibration. Samples were diluted in $2 \% \mathrm{HNO}_{3}$ and measured on an Agilent Technologies 7700 ICP-MS device. Agilent Technologies MassHunter software (version 4.3) was used for data acquisition and analyses.

\section{RESULTS}

\section{Target Irradiations}

The niobium target holder was used to irradiate $250-\mu \mathrm{m}$-thick titanium foils $\left(\rho=4.506 \mathrm{~g} / \mathrm{cm}^{3}\right)$ at $24 \mathrm{MeV}$ and tolerated beam currents of up to $40 \mu \mathrm{A}$. The average $(n=3 \pm 1 \sigma)$ mass of a titanium foil was $91.5 \pm 0.3 \mathrm{mg}$. A 2-piece aluminum target holder was used to irradiate a 400 - $\mu$ m-thick pressed $\mathrm{TiO}_{2}(\rho=$ $\left.4.23 \mathrm{~g} / \mathrm{cm}^{3}\right)$ disk at $17 \mathrm{MeV}$. The average $(n=3 \pm 1 \sigma)$ mass of the disk target was $52.2 \pm 0.4 \mathrm{mg}$. The magnetization of the samarium-cobalt magnets was confirmed after each irradiation $(n=6)$. At a beam current of $20 \mu \mathrm{A}$, thermal damage was observed on the aluminum cap and base; thus, subsequent irradiations were limited to $15 \mu \mathrm{A}$. The tantalum target holder was used to irradiate a 400- $\mu$ m-thick pressed $\mathrm{TiO}_{2}$ disk at $24 \mathrm{MeV}$ at beam currents of up to $40 \mu \mathrm{A}$ for $30 \mathrm{~min}$ with no damage to the target holder or material. The average $(n=3 \pm 1 \sigma)$ mass of the disk target was $110.1 \pm 0.5 \mathrm{mg}$.

\section{Digestion Methods}

Typical digestion times for titanium foils and pressed $\mathrm{TiO}_{2}$ disks were 45 and $90 \mathrm{~min}$, respectively. Titanium foils were digested at $160^{\circ} \mathrm{C}$ using a mixture of $\mathrm{NH}_{4} \mathrm{HF}_{2}$ and $12.1 \mathrm{M} \mathrm{HCl}$. Trace metal analysis of the digestant via ICP-MS showed that the average ( $n$ $=3 \pm 1 \sigma$ ) percentage of titanium foil dissolved in solution was $98 \% \pm 3 \%$. $\mathrm{TiO}_{2}$ disks were digested in 2 steps, and the average $(n=3 \pm 1 \sigma)$ percentage of $\mathrm{TiO}_{2}$ dissolved in solution was $95 \%$ $\pm 1 \%$. These methods were developed using nonirradiated titanium target material, and data from initial experiments are shown in Supplemental Figure 1 (supplemental materials are available at http://jnm.snmjournals.org).

\section{${ }^{43} \mathrm{Sc},{ }^{44 \mathrm{~g}, 44 \mathrm{~m} S c,}{ }^{47} \mathrm{Sc}$, and ${ }^{48} \mathrm{~V}$ Yields from nat $\mathrm{Ti}$ Targets}

The radionuclides, measured by a high-purity germanium detector, were ${ }^{48} \mathrm{~V}\left(\mathrm{t}_{1 / 2}=15.97 \mathrm{~d}, \gamma_{1}=944.1, \gamma_{2}=983.5, \gamma_{3}=1,312.1\right.$ $\mathrm{keV}),{ }^{43} \mathrm{Sc}(372.9 \mathrm{keV}),{ }^{44 \mathrm{~g}} \mathrm{Sc}(1,157.0 \mathrm{keV}),{ }^{44 \mathrm{~m}} \mathrm{Sc}(271.2 \mathrm{keV})$ and ${ }^{47} \mathrm{Sc}(159.4 \mathrm{keV})$. The sample counting time was varied to achieve a minimum photopeak area of 500 counts, and dead time was kept below $5 \%$. The average end-of-bombardment production rate $(n=9 \pm 1 \sigma)$ and predicted rate for each radionuclide are shown in Table 1 . These experimental rates were normalized to $1 \mu \mathrm{A}$.

\section{Branched DGA Resin Separation}

The digestant containing titanium ions, scandium radionuclides, and ${ }^{48} \mathrm{~V}$ was loaded onto branched DGA resin. The bulk titanium target material was eluted from the resin and resulted in an average $(n=6 \pm 1 \sigma)$ titanium recovery factor of $96 \% \pm 5 \%$ in $12 \mathrm{~mL}$ of the load eluate and $20 \mathrm{~mL}$ of eluate 1 . In contrast, scandium radionuclides were strongly adsorbed onto the resin in 7-8 M HCl. No scandium radionuclides were detected in the eluates from the load, eluent 1 , or eluent 2 . The scandium radionuclides were desorbed from the resin in $10 \mathrm{~mL}$ of eluent $3(0.1 \mathrm{M} \mathrm{HCl})$. The isolated scandium radionuclides (eluate 3 ) were free of radionuclidic impurities, including ${ }^{48} \mathrm{~V}$. These data are summarized in Table 2, and they show an average $(n=3 \pm 1 \sigma)$ scandium recovery from titanium foil and $\mathrm{TiO}_{2}$-irradiated targets of $94 \% \pm 1 \%$ and $94 \% \pm 3 \%$, respectively.

Samples taken from the final scandium product after reconstitution showed the presence of nonradioactive contaminants. The identity and average $(n=3 \pm 1 \sigma)$ concentration of contaminants in $400 \mu \mathrm{L}$ of $0.5 \mathrm{M} \mathrm{CH}_{3} \mathrm{CO}_{2} \mathrm{NH}_{4}$ were iron $(1.0 \pm 0.3 \mathrm{mg} / \mathrm{L})$, copper $(0.8 \pm 0.3 \mathrm{mg} / \mathrm{L})$, zinc $(1.3 \pm 0.3 \mathrm{mg} / \mathrm{L})$, vanadium $(0.5 \pm 0.3 \mathrm{mg} / \mathrm{L})$, and aluminum $(0.8 \pm 0.3 \mathrm{mg} / \mathrm{L})$. Scandium was not detected or was below the detection limits of the ICP-MS used in this work. The complete separation and concentration of scandium radionuclides required approximately $180 \mathrm{~min}$.

\section{3,44,47Sc-PSMA-617 Radiolabeling and Specific Uptake in LNCaP Tumor Cells}

PSMA-617 was labeled with ${ }^{43,44,47} \mathrm{Sc}$ in $0.5 \mathrm{M} \mathrm{NH}_{4} \mathrm{CH}_{3} \mathrm{CO}_{2}$ at $95^{\circ} \mathrm{C}$ for $30 \mathrm{~min}$. A more than $99 \%$ radiochemical purity $(10$ $\mathrm{MBq} / \mathrm{nmol}$ ) was measured by high-performance liquid chromatography (Fig. 4$)$. The average $(n=4 \pm 1 \sigma)$ percentage of ${ }^{43,44,47} \mathrm{Sc}-$ PSMA-617 associated with LNCaP cells (Supplemental Fig. 2) was $16.6 \% \pm 1.5 \%$ after $2 \mathrm{~h}$ and $21.9 \% \pm 1.7 \%$ after $4 \mathrm{~h}$ of incubation at $37^{\circ} \mathrm{C}$. The average $(n=4 \pm 1 \sigma)$ nonspecific uptake in PC3 cells (control) and in the presence of 2-(phosphonomethyl) pentanedioic acid was less than $0.5 \%$.

\section{Titanium Recycling}

The combined eluates containing titanium were diluted and $\mathrm{pH}-$ adjusted. Near $\mathrm{pH} 8$ (verified by $\mathrm{pH}$ strip test), a fine white, cloudy precipitate formed. After filtration and combustion, the average $(n=$ $4 \pm 1 \sigma$ ) percentage recoveries of titanium were $103 \% \pm 5 \%$ and $108 \% \pm 8 \%$ from titanium foil and $\mathrm{TiO}_{2}$, respectively.

TABLE 1

Average $(n=9 \pm 1 \sigma$ ) Measured and Predicted Radioactivity of Radionuclides, and Average Production Rate Normalized to $1 \mu \mathrm{A}(21,22)$

\begin{tabular}{lcc}
\hline Radionuclide & Predicted rate & Average rate \\
\hline${ }^{43} \mathrm{Sc}$ & 1.1 & $1.1(0.2)$ \\
\hline${ }^{449 \mathrm{Sc}}$ & 4.3 & $4.2(0.4)$ \\
${ }^{44 \mathrm{~m} S c}$ & 0.20 & $0.11(0.01)$ \\
${ }^{47} \mathrm{Sc}$ & 0.19 & $0.17(0.01)$ \\
${ }^{48} \mathrm{~V}$ & 0.23 & $0.25(0.01)$ \\
\hline
\end{tabular}

Data are $\mathrm{kBq} \cdot \mathrm{s}^{-1} \cdot \mu \mathrm{A}^{-1}$. 
TABLE 2

Average $\left(n=3 \pm 1 \sigma\right.$ ) Initial ${ }^{47} \mathrm{Sc}$ and ${ }^{48} \mathrm{~V}$ Radioactivity and Its Recovery in Each Eluate

\begin{tabular}{ccccccc}
\hline \multicolumn{1}{c}{ Material } & Radionuclide & Initial & Load & E1 & E2 & E3 \\
\hline Titanium foil & ${ }^{47} \mathrm{Sc}$ & $52.3(0.4)$ & $5 \times 10^{-5^{*}}$ & $1 \times 10^{-5^{*}}$ & $1 \times 10^{-5^{*}}$ & $49.0(0.5)$ \\
& ${ }^{48} \mathrm{~V}$ & $66.2(0.6)$ & $63.5(0.3)$ & $2.5(0.3)$ & $0.4(0.1)$ & $1 \times 10^{-5^{*}}$ \\
$\mathrm{TiO}_{2}$ & ${ }^{47} \mathrm{Sc}$ & $29.1(0.7)$ & $3 \times 10^{-5^{*}}$ & $1 \times 10^{-5^{*}}$ & $1 \times 10^{-5^{*}}$ & $27.6(0.6)$ \\
& $48 \mathrm{~V}$ & $38.4(0.8)$ & $35.1(0.2)$ & $3.1(0.3)$ & $0.3(0.1)$ & $1 \times 10^{-5^{*}}$
\end{tabular}

*Minimum detectable radioactivity.

Data are $\mathrm{MBq}$, with uncertainty in parentheses.

\section{DISCUSSION}

Targets were created for the irradiation of $\mathrm{TiO}_{2}$ at a beam current of up to $40 \mu \mathrm{A}$ and an energy of up to $24 \mathrm{MeV}$. The samarium-cobalt magnets (aluminum target) did not lose their magnetism and could play a role in the design of compact cyclotron targets. The tantalum target was robust, and future work will be performed to define the maximum tolerated beam current on $\mathrm{TiO}_{2}$. Further, these data show that ${ }^{43,44,47} \mathrm{Sc}$ can be produced via $\mathrm{TiO}_{2}$ at beam currents greater than those currently used for cyclotron production via $\mathrm{CaO}$ or $\mathrm{CaCO}_{3}(\sim 20 \mu \mathrm{A})$.

The end-of-bombardment production rate of scandium radionuclides and coproduced ${ }^{48} \mathrm{~V}$ at $24 \mathrm{MeV}$ in titanium foils agreed with the predicted rate based on published nuclear datasets for the ${ }^{\text {nat }} \mathrm{Ti}(\mathrm{p}, \mathrm{x})$ reaction (Table 1). Using the same methodology, the end-of-bombardment yields of ${ }^{43,44,47} \mathrm{Sc}$ from enriched $\mathrm{TiO}_{2}$ target material were predicted for the ${ }^{46,47,50} \mathrm{Ti}(\mathrm{p}, \alpha)$ nuclear reactions (Supplemental Fig. 3) at 1, 4, and $24 \mathrm{~h}(7,26,27)$. These yields (MBq-GBq) obtained from enriched titanium nuclei would be suitable for preclinical and in some cases clinical investigations.

Previously reported methods for digestion of $\mathrm{TiO}_{2}$ used concentrated hydrogen fluoride, with some methods requiring hours to reach completion (2-6 h). These methods could result in the loss of at least one ${ }^{43,44} \mathrm{Sc} \mathrm{t}_{1 / 2}$. The digestion methods in this work use pressure, heat, and the in situ generation of approximately $1.0 \mathrm{M}$ hydrogen fluoride via the reaction of $\mathrm{NH}_{4} \mathrm{HF}_{2}$ with $12.1 \mathrm{M} \mathrm{HCl}$

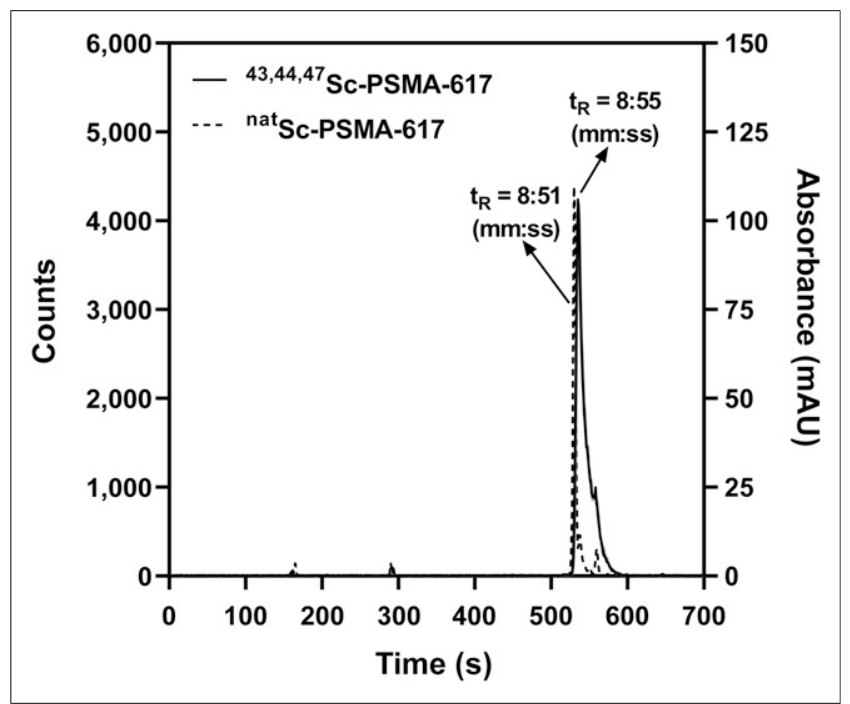

FIGURE 4. Solid line shows radiochromatogram of ${ }^{43,44,47}$ Sc-PSMA617. Dashed line shows absorbance of natSc-PSMA-617 at $280 \mathrm{~nm}$. $\mathrm{AU}=$ arbitrary units.
(28). The results showed that greater than $95 \%$ of titanium foil and $\mathrm{TiO}_{2}$ was dissolved in 45 and $90 \mathrm{~min}$, respectively. The closed perfluoroalkoxy alkane vessels used in this work were inexpensive and durable at temperatures of up to $250^{\circ} \mathrm{C}$. These data support future efforts to characterize and optimize the digestion parameters to further decrease digestion times for titanium foil and $\mathrm{TiO}_{2}$.

Branched DGA and DGA resins have been used to purify scandium in multiple reports $(8,17,29)$. On the basis of the equilibrium dissociation constants determined in this work for scandium, titanium, and vanadium (Supplemental Fig. 4), the separation method developed in this work was predicted to separate scandium from titanium and vanadium and was confirmed by determining the scandium decontamination factor relative to each contaminant. On the basis of Table 2, the decontamination factor for ${ }^{47} \mathrm{Sc}$ relative to ${ }^{48} \mathrm{~V}$ was greater than $6 \times 10^{6}$ and $3 \times 10^{6}$ for scandium isolated from titanium foil and $\mathrm{TiO}_{2}$, respectively. Similarly, titanium present in the recovered scandium fractions was below the ICP-MS detection limits $(\sim 1 \mu \mathrm{g} / \mathrm{L})$; thus, the data show that the decontamination factor of ${ }^{47} \mathrm{Sc}$ relative to titanium was greater than $2.8 \times 10^{5}$ and $1.6 \times 10^{5}$ for titanium foil and $\mathrm{TiO}_{2}$, respectively. These data show that scandium was isolated with little contamination from titanium and vanadium. The overall scandium recovery factors agreed with previously reported procedures using DGA resins $(8,17,30)$. Trace metal analyses via ICP-MS of the titanium-containing digestants and recovered scandium fractions showed the presence of iron, copper, zinc, vanadium, and aluminum. These transition metal contaminants can reduce radiolabeling yield by competing with scandium radionuclides for ligand binding. The sources of these impurities can be from the target material or environmental contamination. The average concentrations of these impurities were between 0.5 and $1.3 \mathrm{mg} / \mathrm{L}$, which compared well with previous reports $(17,30)$.

To demonstrate the efficacy of these methods, a proof-ofconcept study was conducted using PSMA-617 radiolabeled with scandium. The results showed specific targeting of the PSMA receptors on $\mathrm{LNCaP}$ cells using ${ }^{43,44,47} \mathrm{Sc}$-PSMA-617 at a molar activity of $10 \mathrm{MBq} / \mathrm{nmol}$.

Historically and in recent reports, titanium has been precipitated with aqueous ammonia solutions at $\mathrm{pH} 8(8,31)$. In this work, a titanium precipitant was obtained using an aqueous ammonia solution to adjust the bulk medium to $\mathrm{pH} 8$. After sufficient time for aggregation and sedimentation, the precipitate was filtered and combusted. The typical concentration of titanium in the filtrate was below $100 \mu \mathrm{g} / \mathrm{L}(\sim 50 \mu \mathrm{g})$, which indicated that the percentage loss of titanium after precipitation was less than $0.1 \%$. The mass recoveries of titanium exceeded $100 \%$, as may be attributed to 2 factors: etching of glass wool by hydrogen fluoride generated in situ, and incomplete combustion of the filter paper or presence 
of water. These data show that the recovery of titanium in the oxide form with aqueous ammonia solution is an effective approach to recycling titanium. Additional work will be performed to reduce the introduction of impurities so as to avoid buildup of contaminants during iterative uses of this method.

\section{CONCLUSION}

In this study, we investigated the feasibility of producing the theranostic radionuclides of scandium on a proton accelerator using a robust and unified process. Results from this work showed that routine production of ${ }^{43,44,47} \mathrm{Sc}$ could be accomplished using enriched $\mathrm{TiO}_{2}$. Importantly, our findings showed that $\mathrm{TiO}_{2}$ targets may tolerate beam currents greater than $30 \mu \mathrm{A}$ using the target holders designed in this work, that $\mathrm{TiO}_{2}$ can be digested via a 2-step process in 90 min, and that digested titanium may be efficiently recovered via alkali precipitation with aqueous ammonia solution. Future work should investigate the maximum tolerated beam current on $\mathrm{TiO}_{2}$ using these target holders and any impact on downstream chemistry that may be caused by the increased heat deposition in the target material. Additionally, these efforts should seek to better understand and optimize the digestion methods developed in this work in order to further reduce digestion times. Finally, the method to precipitate titanium should be modified to remove sources of silicon. Ultimately, the results in this work showed the potential promise in using enriched titanium targets to produce these matched-pair theranostic radionuclides of scandium.

\section{DISCLOSURE}

This work was supported by the Department of Energy Isotope Program under grant DESC0020197. No other potential conflict of interest relevant to this article was reported.

\section{ACKNOWLEDGMENTS}

We would like to thank the UAB Cyclotron Facility for TR24 irradiations.

\section{KEY POINTS}

QUESTION: Is production of the theranostic radionuclides of scandium feasible using enriched $\mathrm{TiO}_{2}$ as a target material?

PERTINENT FINDINGS: The theranostic radionuclides of scandium were produced using naturally isotopic $\mathrm{TiO}_{2}$ on a proton accelerator at energies of up to $24 \mathrm{MeV}$. These targets were rapidly digested in $90 \mathrm{~min}$, followed by scandium purification using ion-exchange chromatography. This work showed a $94 \%$ recovery of scandium radionuclides and demonstrated a simple method to recover digested target material.

IMPLICATIONS FOR PATIENT CARE: The findings add to efforts at identifying easily adoptable methods to produce theranostic radionuclides of scandium, which are increasingly being used in clinical and preclinical studies.

\section{REFERENCES}

1. NuDat 2.8. Brookhaven National Laboratory website. https://www.nndc.bnl.gov/ nudat2/. Data extracted February 17, 2020. Accessed August 24. 2020.
2. Maurer T, Eiber M, Schwaiger M, Gschwend JE. Current use of PSMA-PET in prostate cancer management. Nat Rev Urol. 2016;13:226-235.

3. Hennrich U, Kopka K. Lutathera ${ }^{\circledR}$ : The first FDA- and EMA-approved radiopharmaceutical for peptide receptor radionuclide therapy. Pharmaceuticals (Basel). 2019;12:114.

4. Wester HJ, Schottelius M. PSMA-targeted radiopharmaceuticals for imaging and therapy. Semin Nucl Med. 2019;49:302-312.

5. Müller C, Domnanich KA, Umbricht CA, van der Meulen NP. Scandium and terbium radionuclides for radiotheranostics: current state of development towards clinical application. Br J Radiol. 2018;91:20180074.

6. Eppard E, de la Fuente A, Benešová M, et al. Clinical translation and first inhuman use of $\left[{ }^{44} \mathrm{Sc}\right] \mathrm{Sc}$-PSMA-617 for PET Imaging of metastasized castrateresistant prostate cancer. Theranostics. 2017;7:4359-4369.

7. Carzaniga TS, Auger M, Braccini S, et al. Measurement of ${ }^{43} \mathrm{Sc}$ and ${ }^{44} \mathrm{Sc}$ production cross-section with an $18 \mathrm{MeV}$ medical PET cyclotron. Appl Radiat Isot. 2017;129:96-102.

8. Domnanich KA, Eichler R, Müller C, et al. Production and separation of ${ }^{43} \mathrm{Sc}$ for radiopharmaceutical purposes. EJNMMI Radiopharm Chem. 2017;2:14.

9. Walczak R, Krajewski S, Szkliniarz K, et al. Cyclotron production of ${ }^{43} \mathrm{Sc}$ for PET imaging. EJNMMI Phys. 2015;2:33.

10. Krajewski S, Cydzik I, Abbas K, et al. Cyclotron production of ${ }^{44} \mathrm{Sc}$ for clinical application. Radiochim Acta. 2013;101:333-338.

11. Duchemin C, Guertin A, Haddad F, Michel N, Métivier V. Production of scandium- $44 \mathrm{~m}$ and scandium-44g with deuterons on calcium-44: cross section measurements and production yield calculations. Phys Med Biol. 2015;60:6847-6864.

12. Severin GW, Engle JW, Valdovinos HF, Barnhart TE, Nickles RJ. Cyclotron produced ${ }^{44 \mathrm{~g} S c}$ from natural calcium. Appl Radiat Isot. 2012;70:1526-1530.

13. Szkliniarz K, Sitarz M, Walczak R, et al. Production of medical Sc radioisotopes with an alpha particle beam. Appl Radiat Isot. 2016;118:182-189.

14. Frank R. Scandium-44: benefits of a long-lived PET radionuclide available from the ${ }^{44} \mathrm{Ti} /{ }^{44} \mathrm{Sc}$ generator system. Curr Radiopharm. 2012;5:187-201.

15. Domnanich KA, Müller C, Benešová $\mathrm{M}$, et al. ${ }^{47} \mathrm{Sc}$ as useful $\beta^{-}$-emitter for the radiotheragnostic paradigm: a comparative study of feasible production routes. EJNMMI Radiopharm Chem. 2017;2:5.

16. Loveless CS, Radford LL, Ferran SJ, Queern SL, Shepherd MR, Lapi SE. Photonuclear production, chemistry, and in vitro evaluation of the theranostic radionuclide ${ }^{47}$ Sc. EJNMMI Res. 2019;9:42.

17. Rotsch DA, Brown MA, Nolen JA, et al. Electron linear accelerator production and purification of scandium-47 from titanium dioxide targets. Appl Radiat Isot. 2018;131:77-82.

18. Mamtimin M, Harmon F, Starovoitova VN. Sc-47 production from titanium targets using electron linacs. Appl Radiat Isot. 2015;102:1-4.

19. Carzaniga TS, Braccini S. Cross-section measurement of ${ }^{44 \mathrm{~m}} \mathrm{Sc},{ }^{47} \mathrm{Sc},{ }^{48} \mathrm{Sc}$ and ${ }^{47} \mathrm{Ca}$ for an optimized ${ }^{47} \mathrm{Sc}$ production with an $18 \mathrm{MeV}$ medical PET cyclotron. Appl Radiat Isot. 2019;143:18-23.

20. Ziegler JF, Ziegler MD, Biersack JP. SRIM: the stopping and range of ions in matter. Nucl Instrum Methods Phys Res B. 2010;268:1818-1823.

21. Zerkin VV, Pritychenko B. The experimental nuclear reaction data (EXFOR). Nucl Instrum Methods Phys Res A. 2018;888:31-43.

22. Khandaker MU, Kim K, Lee MW, et al. Investigations of the narTi(p,x $)^{43,44 m, 44 g, 46,47,48} \mathrm{Sc}$, ${ }^{48} \mathrm{~V}$ nuclear processes up to 40MeV. Appl Radiat Isot. 2009;67:1348-1354.

23. Otuka N, Takács S. Definitions of radioisotope thick target yields. Radiochim Acta. 2015;103:1-6.

24. Radchenko V, Engle JW, Medvedev DG, et al. Proton-induced production and radiochemical isolation of ${ }^{44} \mathrm{Ti}$ from scandium metal targets for ${ }^{44} \mathrm{Ti} /{ }^{44} \mathrm{Sc}$ generator development. Nucl Med Biol. 2017;50:25-32.

25. Sandell EB. Meaning of the term "separation factor." Anal Chem. 1968;40:834835.

26. Levkovski VN. Middle Mass Nuclides Activation Cross-Sections by Medium Energy Protons and $\alpha$ Particles. Moscow, Russia: Inter-Vesi; 1991.

27. Gadioli E, Gadioli Erba E, Hogan JJ, Burns KI. Emission of alpha particles in the interaction of 10-85 MeV protons with ${ }^{48,50}$ Ti. Z Phys A At Nucl. 1981;301:289-300.

28. Zhang W, Hu Z, Liu Y, Chen H, Gao S, Gaschnig RM. Total rock dissolution using ammonium bifluoride $\left(\mathrm{NH}_{4} \mathrm{HF}_{2}\right)$ in screw-top Teflon vials: a new development in open-vessel digestion. Anal Chem. 2012;84:10686-10693.

29. Valdovinos HF, Hernandez R, Barnhart TE, Graves S, Cai W, Nickles RJ. Separation of cyclotron-produced ${ }^{44} \mathrm{Sc}$ from a natural calcium target using a dipentyl pentylphosphonate functionalized extraction resin. Appl Radiat Isot. 2015;95: 23-29.

30. Alliot C, Kerdjoudj R, Michel N, Haddad F, Huclier-Markai S. Cyclotron production of high purity ${ }^{44 \mathrm{~m}, 44} \mathrm{Sc}$ with deuterons from ${ }^{44} \mathrm{CaCO}_{3}$ targets. Nucl Med Biol. 2015;42:524-529.

31. Gooch FA. On the separation of titanium and aluminum, with a note on the separation of titanium and iron. Proc Am Acad Arts Sci. 1884;20:435-447. 